\title{
Comparative Study on Faecal Contamination and Occurrence of Salmonella spp. and Vibrio parahaemolyticus in Two Species of Shellfish in Morocco
}

\author{
Rachid Boutaib ${ }^{*}$, , Mohamed Marhraoui ${ }^{2}$, Mohamed Karim Oulad Abdellah ${ }^{2}$ and Brahim Bouchrif ${ }^{3}$ \\ ${ }^{1}$ Institut National de Recherche Halieutique, Centre Régional de Tanger. B.P: 5268. Dradeb, Tanger, Morocco. \\ ${ }^{2}$ Institut National de Recherche Halieutique, Station RSSL Port M'Diq. B.P: 31, Tétouan. Morocco. \\ ${ }^{3}$ Institut Pasteur du Maroc, Casablanca, Morocco
}

\begin{abstract}
Background: Analysis of bivalves for microbial bacteria is a tool for sanitary control. Methodology: 104 samples of bivalves made up of smooth Venus (Callista chione) and red cockles (Acanthocardia tuberculatum) were analysed for Escherichia coli by using MPN technique and for Salmonella by method ISO 6579 and Vibrio parahaemolyticus, analysed biochemically and by multiplex PCR.

Results and Conclusions: Seasonal variation of faecal contamination was observed between wet and dry periods in three locations. Prevalence of Salmonella was $8.6 \%$ and onto 47 strains isolated, three serotypes groups were identified as: S. Kentucky, S. Newport and S. Glostrup. Regarding Vibrio parahaemolyticus, prevalence was $8.6 \%$ with 24 isolates identified and confirmed by multiplex PCR as tdh and trh negatives.
\end{abstract}

Keywords: Salmonella, Vibrio parahaemolyticus, E. coli, Multiplex PCR, Bivalves.

\section{INTRODUCTION}

Molluscan shellfish concentrate microorganisms from surrounding waters during the filter-feeding process. Consequently, they are recognized as reservoirs for various microbial pathogens, including faecal bacteria and marine species such as Vibrio spp. Among pathogens bacteria, strains of Salmonella enterica are amongst the most frequent causes of food-borne infections transmitted to humans, mainly from animal products [1]. Their presence in shellfish has a serious consequence and leads to prevention of production and sale until purification. Vibrio parahaemolyticus a normal inhabitant of marine and estuarine environments is involved in causing gastrointestinal illnesses throughout the world due to the consumption of raw, undercooked shellfish or improperly processed seafood [2]. The thermostable direct haemolysin (TDH) and TDH-related haemolysin (TRH) represent the major virulence factors in this pathogen and have been shown to be present in up to $99 \%$ of clinical strains while their presence in environmentally isolated strains is rare [3].

Sanitary quality control of shellfish is primarily based on the numeration of faecal indicators (Escherichia coli) and monitoring of harvesting areas is a key element in many control systems. In addition, monitoring of Salmonella spp. and Vibrio parahaemolyticus, with appropriate action if they are present, provides an additional level of safety for the seafood consumer. Few studies have been conducted in Morocco regarding the presence of $V$. parahaemolyticus and Salmonella spp. in shellfish.

*Address correspondence to this author at the Centre Régional de l'INRH. B.P: 5268. Dradeb 90000, Tanger, Morocco; Tel: 2125399465 75; Fax: 2125393251 39; E-mail: boutaibr@yahoo.fr
The primary aim of this study was to compare, the levels of faecal contamination, as determined by E. coli counts, and the occurrence of the two pathogens between two species of bivalve that both inhabit the benthos. The second aim was to examine prevalence, spatial -temporal distribution of pathogenic bacteria studied. The third aim was to determine the antimicrobial resistance of Salmonella and if Vibrio isolates were virulent or not?

\section{MATERIALS AND METHODS}

\subsection{Study Area and Sample Collection}

The study area is located in North West Mediterranean coast of Morocco which extends from Fnideq to Oued Laou and covers a coastline of approximately $80 \mathrm{~km}$. This coast is one of the most important areas of shellfish production in Morocco and receives a high population of tourists in summer. The molluscan bivalve shellfish species: smooth Venus (Callista chione) and red cockles (Acanthocardia tuberculatum) constitute an abundant natural bed on the coast and are exploited by shellfishermen for sale. Four locations representing the main productive shellfish farming zones were selected for this study and are: Fnideq, M'Diq, Oued Malleh and Oued Laou (Fig. 1). Fnideq location received continuously a lot of waste water from the city which reached bed of bivalves. The other locations are classified category B in Moroccan legislation, but differed one from the other. Then, M'Diq received a rainy channel which drained precipitations during wet period and influenced contamination of bivalves solely during this period. For Oued Malleh, this location received during wet period discharges of this river but in dry period, the river stopped for running. Oued Laou location is localised in a rural zone and is influenced by this river when it rained 


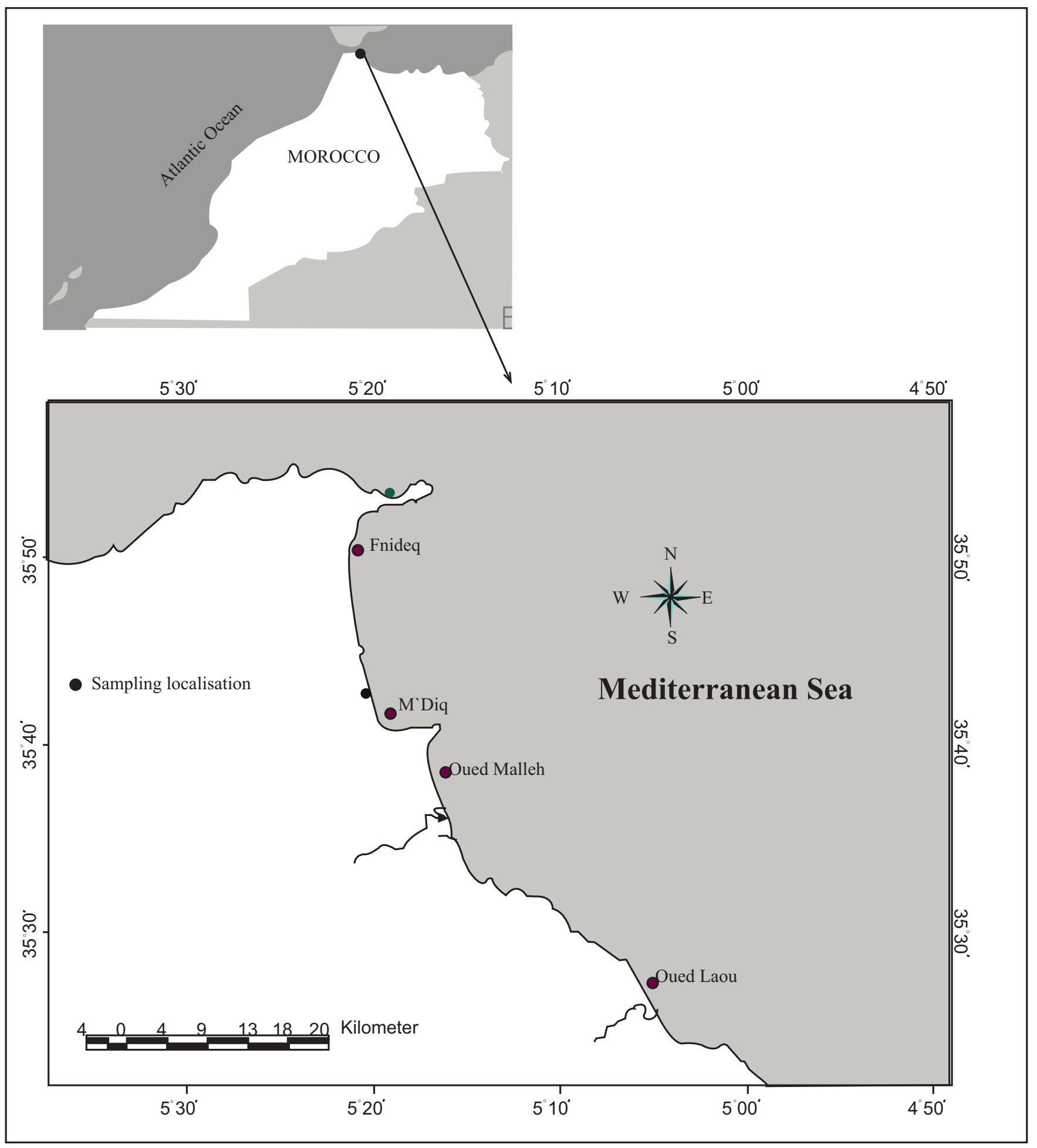

Fig. (1). Map of northwest of Morocco showing the position of sampling locations.

heavy, but generally water quality of this point is good since it didn't receive any urban discharge. Both bivalves were fished by dredging on board boat at a depth of $6 \mathrm{~m}$ to $20 \mathrm{~m}$ from the coastline. Samples were collected monthly from each point localised by GPS over the entire study period (April 2007 - April 2008). A dozen individuals of each bivalve species were retained and placed in a single use plastic bag and then transported to the laboratory under refrigeration $\left(1-8^{\circ} \mathrm{C}\right)$.

\subsection{Enumeration of $E$. coli}

For each bivalve sample, at least six individuals were opened aseptically in a sterile bowl. Approximately 75 to $100 \mathrm{~g}$ of flesh and intervalvular liquid (FIL) were diluted 1:3 with Tryptone salt water (TSW) (Biokar Diagnostics). The mixture was blended in a waring blender during 1 min at $15000 \mathrm{rev} \mathrm{min}^{-1}$. The homogenate was allowed to stand for 15 - $30 \mathrm{~min}$ at room temperature and then further $30 \mathrm{~mL}$ of 
this suspension were diluted with $70 \mathrm{~mL}$ of TSW to obtain a 1: 10 suspension before inoculation into culture media. An aliquot of $10 ; 1$ and $0.1 \mathrm{~mL}$ of consecutive decimal dilutions of the 1: 10 FIL suspension were inoculated into each of five tubes containing $10 \mathrm{~mL}$ of double or single-strength glutamate broth (Biokar diagnostics) and incubated at $37^{\circ} \mathrm{C}$ for 24 hours.

The contents of each tube showing a yellow colour, indicating lactose fermentation and acid production, was then subcultured onto a plate containing Tryptone bile glucuronide agar (TBGA) (Biokar Diagnostics) and incubated at $44^{\circ} \mathrm{C}$ for 24 hours. For the enumeration of the $B$ glucuronidase positive $E$. coli, MPN was determined from the number of subcultures at each dilution yielding blue colonies indicative of $\beta$-glucuronidase activity [4].

\subsection{Statistical Analysis}

To perform the statistical analysis, the variable E. coli was transformed by the $\log (\mathrm{x}+1)$ function for to respond a normal distribution of data. An ANOVA test was performed to detect the statistical significance of factors locations and species. Statistical tests were computed using STATISTICA logiciel version 5, 97 edition.

\subsection{Analysis for Salmonella}

Salmonella isolation and identification were performed as described by [5].

$25 \mathrm{~g}$ of each bivalve flesh were added to $225 \mathrm{~mL}$ of Buffered peptone water (BPW) (Biokar Diagnostics) as preenrichment media and incubated at $37^{\circ} \mathrm{C}$ for $16-20$ hours. One millilitre of pre enriched culture was transferred to 10 $\mathrm{mL}$ of Muller Kauffmann tetrathionate novobiocin broth (MKTTn) (Biokar diagnostics) and $0.1 \mathrm{~mL}$ to $10 \mathrm{~mL}$ of Rappaport - Vassiliadis broth (RV) (Biokar Diagnostics), and these were incubated at $37^{\circ} \mathrm{C}$ and $41.5^{\circ} \mathrm{C}$ respectively for 24 hours. Selective enrichments were streaked onto Xylose lysin desoxycholate agar (XLD) (Biokar diagnostics) and Phenol red brilliant green agar (PRBG) (Biokar diagnostics) and incubated at $37^{\circ} \mathrm{C}$ for 24 hours.

Typical colonies were selected and streaked onto nutrient agar and subjected to initial biochemical screening in Triple sugar iron agar (TSI) (Biokar diagnostics). Cultures showing a reaction typical of Salmonella: an alkaline slant and acid butt, with or without production of $\mathrm{H}_{2} \mathrm{~S}$ were confirmed by biochemical tests on API 20E strip (bioMérieux; Marcyl'Etoile, France). The strains identified biochemically as Salmonella spp were subjected to serotyping according to Kauffman - White diagram [6].

\subsection{Salmonella Serotyping}

All Salmonella isolates were serotyped by seroagglutination with commercial antisera (Statens Serum Institut, Copenhagen, Denmark). Polyvalent Salmonella $\mathrm{O}$ and $\mathrm{H}$ antisera were used to obtain a presumptive diagnosis and the definitive antigenic designation was then determined with monovalent antisera.

\subsection{Antimicrobial Susceptibility Testing}

Isolates were screened for susceptibility to 16 antibiotics on Mueller-Hinton agar (Oxoid, Basingstoke, Hampshire, United Kingdom) by disk diffusion. The following disks
(Oxoid) were used: amikacin $(30 \mu \mathrm{g})$, apramycin $(15 \mu \mathrm{g})$, amoxicillin-clavulanic acid $(30 \mu \mathrm{g})$, ampicillin $(10 \mu \mathrm{g})$, chloramphenicol $(10 \mu \mathrm{g})$, cefoperazone $(30 \mu \mathrm{g})$, ceftazidime $(30 \mu \mathrm{g})$, colistin $(25 \mu \mathrm{g})$, furazolidone $(15 \mu \mathrm{g})$, gentamicin $(10 \mu \mathrm{g})$, nalidixic acid $(30 \mu \mathrm{g})$, neomycin $(10 \mu \mathrm{g})$, streptomycin $(25 \mu \mathrm{g})$, sulfamethox-azole-trimethoprim $(25 \mu \mathrm{g})$, sulfonamide compound $(300 \mu \mathrm{g})$, and tetracycline (10 $\mathrm{gg})$.

\subsection{Detection of Vibrio Parahaemolyticus}

$25 \mathrm{~g}$ of each bivalve flesh were added to $225 \mathrm{~mL}$ of Alkaline peptone water (APW) (Biokar Diagnostics) and incubated at $37^{\circ} \mathrm{C}$ for $18-24$ hours. An aliquot was transferred to Thiosulfate citrate bile saccharose agar (TCBS) (Biokar Diagnostics) and the plates incubated at $37^{\circ} \mathrm{C}$ for 24 hours. The blue or green characteristic colonies of Vibrio were selected and subcultured to nutrient agar with $2 \% \mathrm{NaCl}$ for purity. Gram staining and cytochrome oxidase activity were performed. Isolates Gram-negative, positive oxidase were further identified using the API $20 \mathrm{E}$ system, $\mathrm{ADH}, \mathrm{LDC}$ and ODC tests and culture in $0,3,6,8$ and $10 \%$ $\mathrm{NaCl}$ peptone water were used to identify the Vibrio. Potentially pathogenic strains of Vibrio parahaemolyticus were subjected to multiplex PCR for the presence of $R 72 \mathrm{H}$, tdh and trh.

For DNA extraction, the isolate was cultured overnight on a Tryptone Soy Agar (TSA) (Biokar Diagnostics) plate containing $3 \% \mathrm{NaCl}$ at $37^{\circ} \mathrm{C}$. Several well-grown colonies were chosen and resuspended in $300 \mu \mathrm{l}$ sterile distilled water and boiled for $8 \mathrm{~min}$ to lyse the cells. The lysate was centrifuged and the supernatant containing DNA was used directly as a template in the PCR. Primers used at concentrations of $5 \mu \mathrm{M}$ were VP32 (5'CGAATCCTTGA ACATACGCAGC3') and VP33 (5'TGCGAATTCGATAG GGTGTTAACC3') that amplify a fragment of 387 bp; L.T DH (5'GTAAAGGTCTCTGACTTTTGGAC3') and R.TDH (5'TGGAATAGAACCTTCATCTTCACC3') that amplify a fragment of $270 \mathrm{bp}$; L.TRH (5'TTGGCTTCGATATTTTC AGTATCT3') and R.TRH (5'CATAACAAACATATGCCC ATTTCC3') that amplify a fragment of $486 \mathrm{bp}$. Amplification products were separated on $2 \%$ horizontal agarose gels, stained with ethidium bromide and visualized under UV light. PCRs were carried out in a thermocycler with the following reaction conditions: denaturation at $94^{\circ} \mathrm{C}$ for $5 \mathrm{~min}$, followed by 40 cycles of denaturation at $94^{\circ}$ for $30 \mathrm{~s}$, primer annealing at $58^{\circ} \mathrm{C}$ for $45 \mathrm{~s}$, and primer extension at $68^{\circ} \mathrm{C}$ for 75 s. A final extension was performed at $68^{\circ} \mathrm{C}$ for $7 \mathrm{~min}$ [7].

\section{RESULTS}

\subsection{Enumerations of $E$. coli}

$63.5 \%$ and $52 \%$ of samples respectively for smooth Venus and red cockles were in compliance with the regulatory threshold $230 \mathrm{E}$. coli $/ 100 \mathrm{~g}$ FIL. The level of $E$. coli ranged from $2.0 \times 10^{1}$ to $5.4 \times 10^{3} \mathrm{MPN} E$. coli $/ 100 \mathrm{~g}$ FIL in cockles and smooth Venus for the two locations of M'Diq and Oued Laou. Whereas, it ranged from $2.0 \times 10^{1}$ to 1.8 $\times 10^{4} \mathrm{MPN}$ E. coli/100 g FIL in bivalves of Fnideq and Oued Malleh. E. coli concentrations were similar or occasionally higher in cockles than in smooth Venus in each location. At the three locations of M'Diq, Oued Malleh and Oued Laou, a seasonal variation of the faecal contamination was noted 


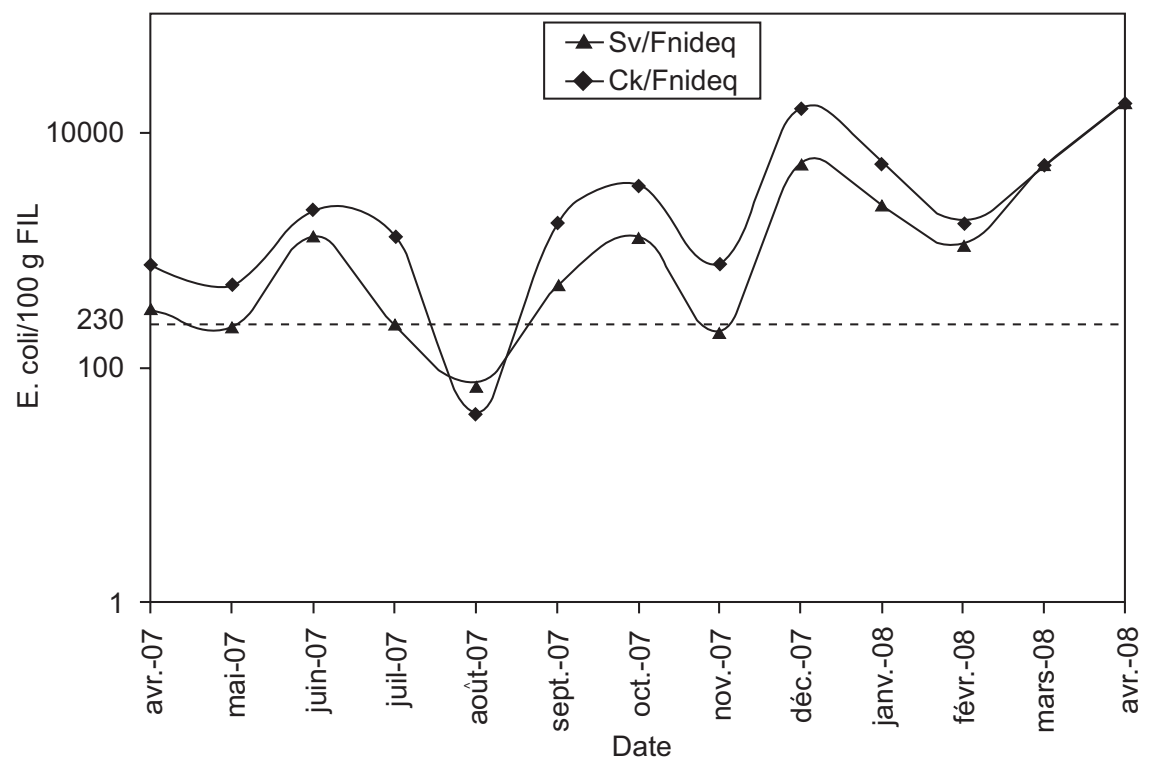

Fig. (2). Monthly variation of $E$. coli counts in two bivalves at Fnideq.

with $E$. coli concentrations often exceeding the threshold of 230 E. coli $/ 100 \mathrm{~g}$ FIL in both species in the wet period (October - April) while those in the dry period (May September) were all in compliance (Figs. 3-5). Whereas, at Fnideq, there was no seasonal variation and during the entire monitoring period, the concentrations of E. coli were almost very high in both bivalve species (Fig. 2).

Statistical analysis by ANOVA test (Table 1) showed that there was significant difference in the faecal contamination between cockles and smooth Venus $\left(\mathrm{F}=4.999^{*}, \mathrm{p}<0,027\right)$. Moreover, a significant difference did exist between locations $\left(\mathrm{F}=13,017^{*}, \mathrm{p}<0,000\right)$. The post hoc comparison by Duncan test showed that faecal contamination in Fnideq differed significantly from the other locations. But there wasn't any interaction between location and species $(\mathrm{F}=0.079, \mathrm{p}<0.971)$.
Table 1. Analysis of variance of $E$. coli with respect to factors species and location

\begin{tabular}{|c|c|c|c|c|}
\hline Source of Variation & df & MS & F & p \\
\hline \hline Species & 1 & 3.146 & $4.999^{*}$ & 0.027 \\
Location & 3 & 8.193 & $13.017^{*}$ & 0.000 \\
Interaction & 3 & 0.049 & 0.079 & 0.971 \\
\hline
\end{tabular}

\subsection{Prevalence of Salmonella}

Salmonella spp. was detected in 9 of $104(8.6 \%)$ samples analyzed. The highest prevalence of Salmonella bacteria was detected in cockles with 7 positive samples against 2 positive samples of smooth Venus. The frequency of isolation of Salmonella for each point was: $26.9 \%(7 / 26), 7.7 \%(2 / 26)$,

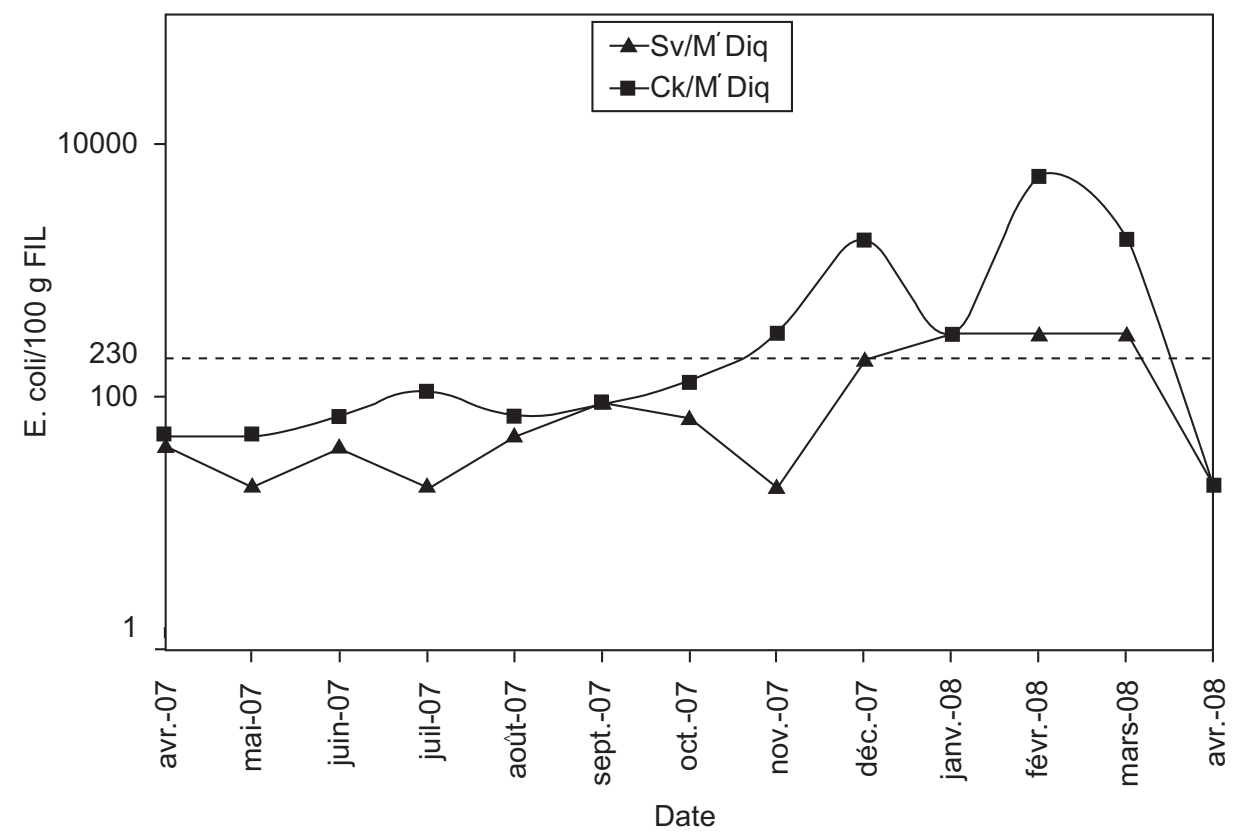

Fig. (3). Monthly variation of E. coli counts in two bivalves at M'Diq. 


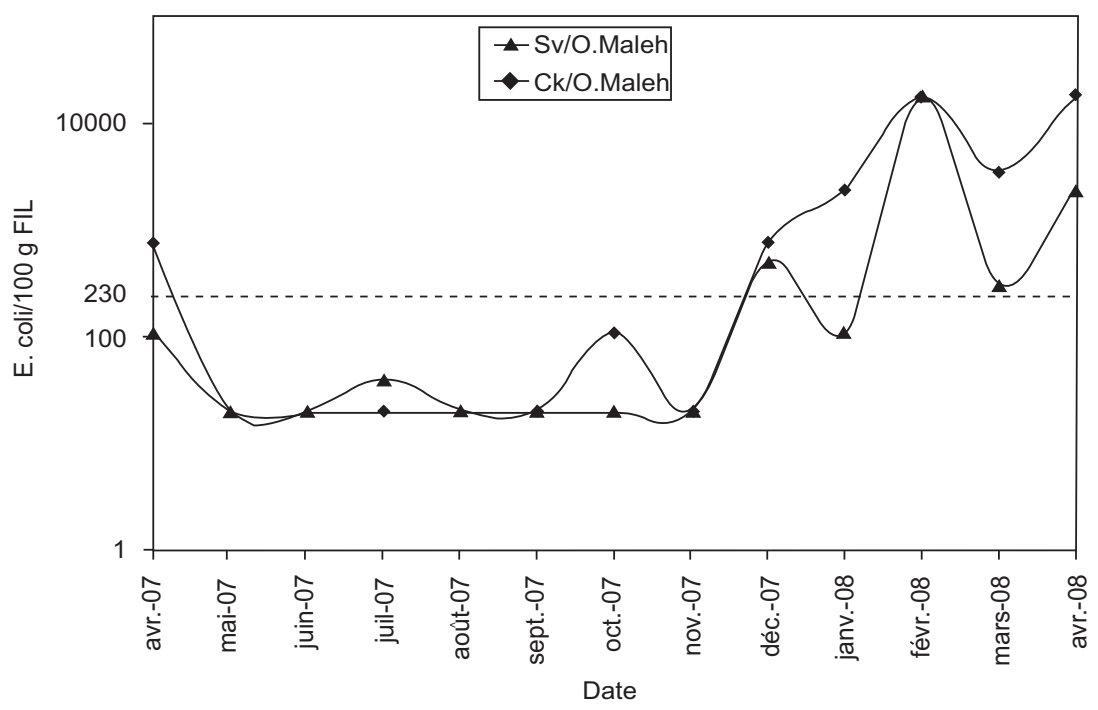

Fig. (4). Monthly variation of $E$. coli counts in two bivalves at Oued Malleh.

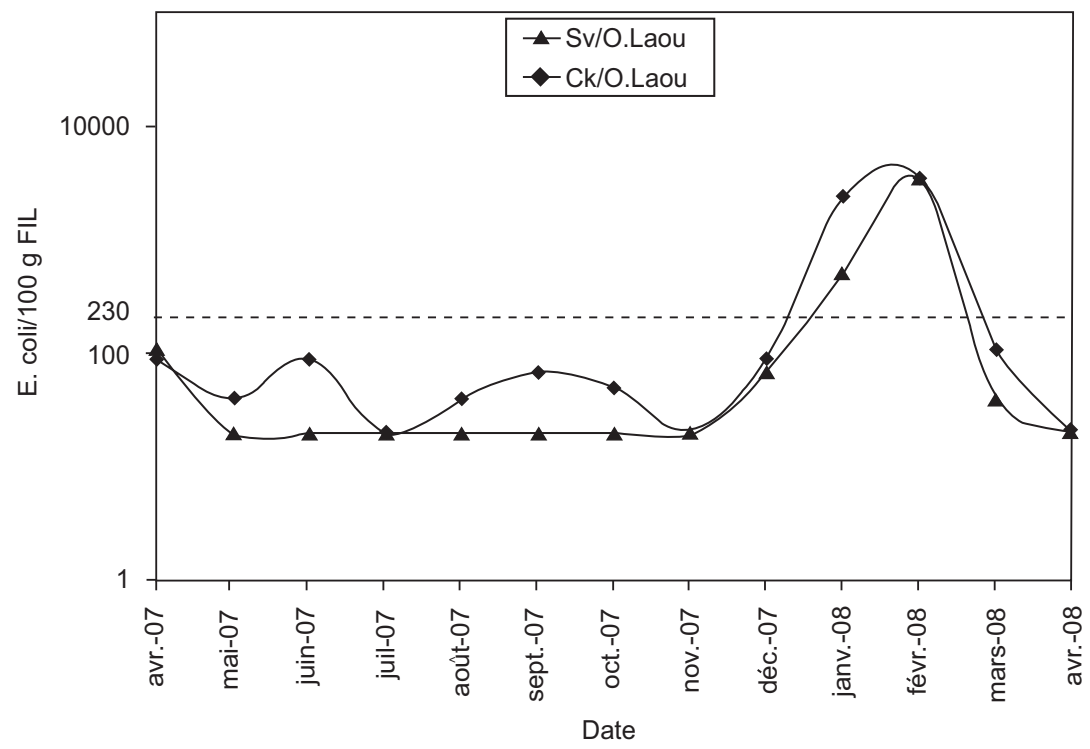

Fig. (5). Monthly variation of E. coli counts in two bivalves at Oued Laou.

0\% (0/26), respectively for Fnideq, Oued Malleh, M'Diq and Oued Laou. Four samples of cockles from Fnideq were positive against three of smooth Venus; while in Oued Malleh, only two samples of cockles were positive. Almost Salmonella spp. strains were isolated during the period: September 2007 - March 2008, which corresponded to main rainy period of the year. After biochemical identification on API 20E strip, onto 9 samples positives of Salmonella, 47 strains were isolated. Serotyping of isolates revealed three different serotypes: $S$. Kentucky (53.2\%) which was dominant; $S$. Glostrup (27.7\%) and $S$. Newport (19.1\%). S. Glostrup was not detected in any samples from Oued Malleh.

For each positive Salmonella result, the corresponding concentration of $E$. coli was determined in order to see if there was presence of Salmonella when the E. coli contamination was less than the threshold 230 (Table 2). From our results, it noted that the minimum level of E. coli corresponding to detection of Salmonella was $1.1 \times 10^{3}$ for smooth Venus against $1.7 \times 10^{3} \mathrm{E}$. coli/100 g FIL for cockles. The $E$. coli concentrations were significantly higher than the regulatory threshold of $230 \mathrm{E}$. coli/100 g FIL.

\subsection{Resistance to Antimicrobials}

Drug susceptibility assay revealed that all Salmonella Kentucky isolates investigated were fully resistant to ciprofloxacin, but no resistance to cephalosporins. One isolate of Salmonella Newport were resistant to ampicillin, tetracyclin and chloramphenicol. All Salmonella Glostrup isolates were resistant to ampicilin, tetracycline and nalidixic-acid. The presence of resistant and multidrugresistant strains linked to an enteric bacteria like: Salmonella Kentucky and Glostrup occurring in the marine environment may be considered a very preliminary evidence suggesting the extensive use of antibiotics in veterinary and medical practices for the control of bacterial diseases in the region, as has been reported for other regions [8]. 
Table 2. Faecal contamination level corresponding to presence of Salmonella in bivalves

\begin{tabular}{|c|c|c|c|c|c|c|c|}
\hline $\begin{array}{c}\text { Month } \\
\text { Specie/Location }\end{array}$ & Jun. 2007 & Sep.2007 & Oct.2007 & Dec. 2007 & Jan. 2008 & Feb. 2008 & Mar. 2008 \\
\hline \hline $\begin{array}{c}\text { S.v/Fnideq } \\
\text { Ck/Fnideq } \\
\text { Ck /Oued Malleh }\end{array}$ & $1.3 \times 10^{3}$ & $1.7 \times 10^{3}$ & $3.5 \times 10^{3}$ & $\begin{array}{c}5.4 \times 10^{3} \\
1.6 \times 10^{4}\end{array}$ & & $1.1 \times 10^{3}$ & $5.4 \times 10^{3}$ \\
\hline
\end{tabular}

N.B: S.v: Smooth Venus; Ck: Cockles.

\subsection{Prevalence of Vibrio parahaemolyticus}

Of the 104 samples of cockles and smooth Venus examined, $8.6 \% \quad(9 / 104)$ were positive for Vibrio parahaemolyticus. The frequency of isolation by each point was: $27 \%(7 / 26), 3.8 \%(1 / 26), 0 \%(0 / 26)$ and $3.8 \%(1 / 26)$ respectively for Fnideq, M'Diq, Oued Malleh and Oued Laou locations. The prevalence was almost similar in the two bivalves (5 samples in cockles against 4 in smooth Venus). Regard to the seasonality of $V$. parahaemolyticus we found: $38 \%(9 / 24), 38 \%(9 / 24), 12 \%(3 / 24)$ and $12 \%(3 / 24)$ respectively for autumn, winter, spring and summer. From the nine positives samples, 24 strains of this bacterium were isolated by biochemical tests. Multiplex PCR was carried out in order to examine the virulence capacity of these strains. All isolated strains of presumptive $V$. parahaemolyticus had taxonomic marker R72H (Fig. 6) and the two genes coding for haemolysins TDH and TRH were absent from all isolates V. parahaemolyticus.

\section{DISCUSSION}

The mean level of faecal contamination, as determined by $E$. coli, was higher in cockles than in smooth Venus in each location, and this difference was statistically significant. So in several times, cockles showed higher levels of faecal contamination than smooth Venus whether in wet period or whether in dry period. When the receiving waters were natural and less polluted, especially during the dry period, the levels of faecal contamination were generally low and less than the threshold 230 and sometimes similar in both bivalve species particularly at M'Diq, Oued Malleh and
Oued Laou. But when the receiving waters were polluted by discharge of waste water or the effect of rainfall (just few days before sampling), the level of contamination became high or very high in both bivalves. Concentrations of $E$. coli exceeding the threshold of $230 \mathrm{E}$. coli /100 g FIL observed in both bivalve species in the wet period in 3 locations (M'Diq, Oued Malleh and Oued Laou) were to be attributed to effect of intense rainfall a few days before sampling. Under their effects, there were scrubbing of the grounds and transit of the microbial contaminants towards the coast. In the dry period, rainfall was rare and rivers didn't load discharges or waste water to the locations which could affect adversely their quality. We observed a seasonal variation of $E$. coli contamination of the bivalves harvested from the three locations (M'Diq, Oued Malleh and Oued Laou). All the locations were situated at the mouth of rivers (Oued), which didn't discharge waste water to coast. But also, when it rained just few days before sampling in wet period, there were leaching of the ground and carriage out of contaminants to coast. The sedentary filter feeding organisms (bivalves) obtain food by filtering a large volume of water and in the process they accumulate particulate matter including pathogenic bacteria in their tissues. In dry period, these locations didn't receive discharge, so the level of E. coli contamination was at the minimum. At Fnideq, high concentrations of $E$. coli detected through most of the year were due mainly to continuous discharge in Fnideq river of waste water emanating of the city (that count more than 52.000 people) and discharging near to the sampling point. This waste water didn't undergo any treatment.

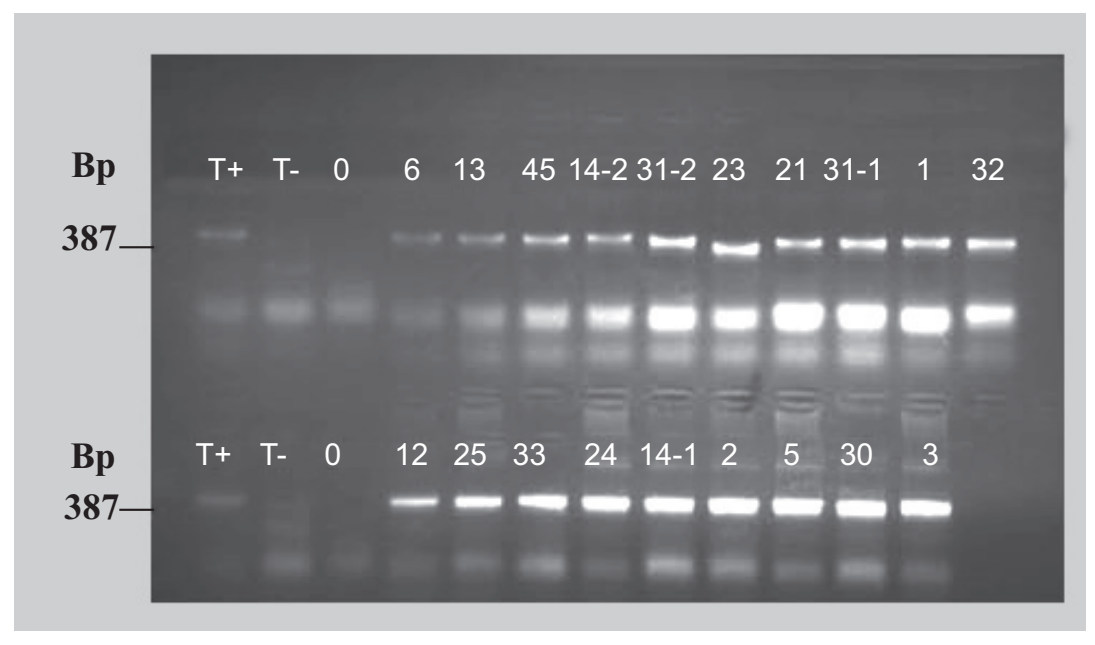

Fig. (6). Results of PCR multiplex on gel electrophoresis: T+: Positive control ( $V$. parahaemolyticus trh and tdh negatives); T-: Negative control; (V. alginolyticus); 0: white control. Lines: 6,13,45,14-2,31-2,23,21,31-1,1,32,12,25,33,24,14-1,2,5,30,3: isolated strains of Vibrio parahaemolyticus. 
No information was found in the scientific literature regarding the relative microbiological contamination of the two bivalve species studied in this work. The differences may be due to some of the following factors: physiology difference of the two bivalves mainly in digestive apparatus, life mode ecology where cockles lived on bottom surface at the first centimetres, while the smooth Venus lived more hidden in the bottom.

With respect to Salmonella, in a previous study undertaken in Tunisia on Ruditapes decussatus, the occurrence of Salmonella was less than 1\% [9]. However, in clams from Mozambique, the prevalence of this pathogen was very high with $75.7 \%$ of samples with a difference between dry season (when three on eleven samples were positive) and wet period where all samples $(n=22)$ were positive for Salmonella [10]. On other study done on mussels and Donax spp in Albania, prevalence of Salmonella was $0.2 \%$ out of 458 examined samples of bivalves, although the majority of the studied points are of class B [11]. In addition, the incidence of Salmonella in mussels, cockles, clam, oysters and sea water of Galicia in Spain was $2.4 \%$ out of 5384 samples examined on the whole and onto 127 strains of Salmonella, 20 different serovars with prevalence for $S$. Senftenberg which accounts for $42.5 \%$, then $S$. Typhimurium with a percentage of $15 \%$ and $S$. Agona with a percentage of $9.4 \%$ [12]. Other study undertaken on oysters of the USA found a prevalence of Salmonella similar at our results with $7.4 \%$ out of 1296 samples examined and reported a prevalence of $S$. Newport with a prevalence of $77.2 \%$ out of 101 strains of isolated Salmonella [13]. In a study undertaken in Morocco, onto 801 samples examined of mussels, seawater and marine sediment from Agadir coast, three serotypes were found: $S$. Blockley represented $43.8 \%$ of all Salmonella strains and was identified in mussels and sediment samples. S. Kentucky $(29.8 \%)$ was detected almost exclusively in mussels, whereas S. Senftenberg (26.3\%) was detected in sediment and seawater [14]. In our study, we can say that Salmonella in bivalve species was only found in the most polluted locations and especially cockles (6 samples against 3 of smooth Venus). This appears normal, considering cockles proved more contaminated in general than smooth Venus in E. coli and consequently retain more bacteria of faecal origin (Salmonella). Concerning isolation of Salmonella from environment in Morocco, we found the same serotype $S$. Kentucky in our samples of bivalves and in mussels from Agadir coastal respectively with a percentage of $53.2 \%$ and $29.8 \%$ [14].

With respect to Vibrio parahaemolyticus, in a study on the mussels of the Wadden Sea in Germany, of 86 strains isolated of Vibrio, $39.5 \%$ were shown to be Vibrio parahaemolyticus [15]. In other study on mussels of the Adriatic Sea in Italy, onto 144 samples, $24.3 \%$ were shown Vibrio parahaemolyticus, but in other work from the same region, $V$. parahaemolyticus was found with a prevalence of $11.6 \%$ on 559 samples $[16,17]$. In the last study, non $V$. parahaemolyticus $t d h$ positive was found, but $7.7 \%$ were $t r h$ positive. In addition, in a study taken in Europe, Vibrio parahaemolyticus was detected in mussel samples from the Netherlands with a prevalence of $2.8 \%$, in Spain with $7 \%$, and in oysters from the Netherlands with $2.4 \%$ [18]. In a study on the mussels of the French coasts, prevalence of
Vibrio parahaemolyticus was found with a percentage of $28.2 \%$ [19].

In the present study, multiplex PCR confirmed that the 24 strains of $V$. parahaemolyticus isolated were negative for $t d h$ and $t r h$, showing that the bivalves were not a health risk with regard to this pathogen. This result was in agreement with others authors who found that 1 to $3 \%$ of the isolates of environmental origin produce haemolysins TDH and/or TRH $[20,21]$. In the same way, on a total of 1500 strains of Vibrio parahaemolyticus isolated from the watery environment of Bangladesh, 5 strains were found positive $t d h$ and no strain has gene of virulence trh [22]. In another study reported, 4 strains out of 46 of $V$. parahaemolyticus, were shown to contain the $t d h$ gene, but none contained the trh gene [23].

In this study, it seemed that the faecal contamination (counts of $E$. coli) was high through the year and above of the threshold $230 \mathrm{E}$. coli/100 g FIL in both bivalves harvested from Fnideq location. Also, the prevalence of Salmonella $(26.9 \%)$ was high in this point owing to continuous discharging of a lot of waste water nearly of the point. Regard as the other locations, there was a seasonal variation of faecal contamination between wet and dry periods of the year. In dry period, level of E. coli was very low in both bivalves but increased more than the threshold 230 E. coli/100 g FIL when it rained just before sampling. Presence of Salmonella especially in bivalves of Fnideq and Oued Malleh constitute a health problem for consumers of bivalves. Non presence of $V$. parahaemolyticus $t d h$ and $t r h$ positive was good for consumers, but an implementation of a monitoring program of these bacterial pathogens will be benefit for safety of the consumers. On the basis of the extent of faecal contamination, the bivalves of Fnideq and Oued Malleh must undergo heat treatment in an approved unit, while the lower levels of contamination of the bivalves at M'Diq and Oued Laou means that they can be sold after adequate purification.

\section{ACKNOWLEDGEMENTS}

The authors gratefully thank Dinay Company direction for financial support of this study and the Institute Pasteur in Casablanca for technical assistance of this work. Also, we thank appreciatively Dr. Ron Lee from CEFAS for reviewing the manuscript.

\section{CONFLICT OF INTEREST}

No conflict of interests is declared.

\section{REFERENCES}

[1] Desenclos JC, Bouvet P, Pierre V, et al. Epidémiologie des infections à Salmonella: tendances récentes en France et en Europe. Bull Soc Fr Microbiol 1996; 11: 209-15.

[2] Potasman I, Paz A, Odeh M. Infectious outbreaks associated with bivalve shellfish consumption: a worldwide perspective. Clin Infect Dis 2002; 35: 921-8.

[3] US Food and Drug Administration (US FDA). Draft risk assessment on the public health impact of Vibrio parahaemolyticus in raw molluscan shellfish. Centre for Food Safety and Applied Nutrition: US FDA 2001.

[4] ISO/TS 16649-3: Horizontal method for the enumeration of $\beta-$ glucuronidase-positive Escherichia coli - Part 3: Most probable number technique using 5-bromo-4-chloro-3-indolyl- $\beta$-Dglucuronide. In: Annual report 2005, ed. International Organization for Standardization 2005. 
[5] ISO 6579. Horizontal method for the detection of Salmonella spp. (including S. Typhi and S. Paratyphi). In: Annual report 2002, ed. International Organization for Standardization 2002.

[6] Popoff MY. Antigenic formulas of the Salmonella serovars, 8th ed. WHO collaborating center for reference and research on Salmonella. Institut Pasteur, Paris. France 2001.

[7] Green M, Buenaventura E, Wong C, Liu J. Détection spécifique des souches de Vibrio parahaemolyticus à l'aide d'une réaction en chaîne de la polymérase (PCR) multiplex basée sur le marqueur taxonomique $\mathrm{R} 72 \mathrm{H}$ et les gènes de l'hémolysine TDH et TRH. Méthode de laboratoire MFLP - 23. Direction générale des produits de santé et des aliments. Ottawa, Canada 2006.

[8] Harwood VJ, Whitlock J, Withington VH. Classification of the antibiotic resistance patterns of indicator bacteria by discriminant analysis: use in predicting the source of faecal contamination in subtropical Florida waters. Appl Environ Microbiol 2000; 66: 3698-704.

[9] El Merji S, El Bour M, Boukef I, Mraouna R, Benaissa R. Prevalence of Salmonella serovars in Ruditapes decussatus from Tunisian coasts. Association africaine de microbiologie et d'hygiène alimentaire, Sousse, Tunisie 2007; 19(55): 82-5.

[10] Collin B, Holm ASR, Hernroth B. Faecal contaminants in edible bivalves from maputo bay, mozambique: seasonal distribution, pathogenesis and antibiotic resistance. Open Nutr J 2008; 2: 86-93.

[11] Sulaja K, Telo D, Shalari Y, Aleksi P. Monitoring of bacteriological indicators and Salmonella spp. in production zones of bivalve molluses in Albania on 2004. balwois.com/balwois/admini stration/full_paper/ffp-825.pdf [Consulted in March 4, 2011].

[12] Martinez-Urtaza J, Saco M, De Novoa J, et al. Influence of environmental factors and human activity on the presence of Salmonella serovars in a marine environment. Appl Environ Microbiol 2004; 70: 2089-97.

[13] Brands DA, Inman AE, Gerba CP, et al. Prevalence of Salmonella spp. in Oysters in the United States. Appl Environ Microbiol 2005; 893-7.
[14] Setti I, Rodriguez-Castro A, Pata MP, et al. Characteristics and dynamics of Salmonella contamination along the coast of Agadir, Morocco. Appl Environ Microbiol 2009; 75(24): 7700-9.

[15] Lhafi SK, Kuhne M. Occurrence of Vibrio spp. in blue mussels (Mytilus edulis) from the German Wadden Sea. Science Direct. Int J Food Microbiol 2007; 116: 297-300.

[16] Ottaviani D, Santarelli S, Bacchiocchi S, Masini L, Ghittino C, Bacchiocchi I. Presence of pathogenic Vibrio parahaemolyticus strains in mussels from the Adriatic Sea, Italy. Food Microbiol 2005; 22: 585-90.

[17] Ottaviani D, Leoni F, Rocchegiani E, et al. Prevalence, serotyping and molecular characterization of Vibrio parahaemolyticus in mussels from Italian growing areas, Adriatic Sea. Environ Microbiol Rep 2010; 2(1) : 192 -7.

[18] Baylet R, Panayota E, Guyonnet, JP. Pathologies attribuables à la consommation de coquillages. Rev Française des Lab 2004; 359 : 21-31.

[19] Hervio-Heath D, Colwell R, Derrien A, Robert-Pillot A, Fournier JM, Pommopuy M. Occurrence of pathogenic Vibrios in coastal areas of France. J Appl Microbiol 2002; 92: 1123-35.

[20] Wong HC, Shieh WRS, Lee YS. Toxigenic characterization of vibrios isolated from foods available in Taiwan. J Food Prot 1993; 56: $980-2$.

[21] Honda T, Lida T. The pathogenicity of Vibrio parahaemolyticus and the role of thermostable direct haemolysin and related haemolysins. Rev Med Microbiol 1993; 4: 106-13.

[22] Sirajul IM, Tasmin R, Sirajul IK, et al. Pandemic strains of O3:K6 Vibrio parahaemolyticus in the aquatic environment of Bangladesh. Can J Microbiol ISSN 0008-4166. CODEN CJMIAZ 2004; 50(10): 827- 34.

[23] Cabrera-Garcia ME, Salinas CV, Ramırez EIQ. Serologic and molecular characterization of Vibrio parahaemolyticus strains isolated from seawater and fish products of the Gulf of Mexico. Appl Environ Microbiol 2004; 70(11); 6401-06. 